\title{
CURRÍCULO, GÊNERO E FORMAÇÃO DE DOCENTE
}

\section{Curriculum, gender and teacher training}

Ludmila Lins Bezerra - UFVJM/ Brasil.

RESUMO: Este artigo tem o objetivo problematizar na formação (inicial e continuada) docente a importância de se trabalhar e discutir as relações de gênero no espaço escolar. Para isto, partimos de uma pesquisa bibliográfica. Esta pesquisa situa-se no campo dos Estudos de Gênero, currículo e formação docente. Consideramos a necessidade de trabalhos com este tema na escola buscando levar os/as docentes a problematizar e refletir suas práticas pedagógicas. É interessante refletir sobre as disciplinas, metodologias e conteúdos sob a perspectiva dos estudos de gênero. Assim, torna-se essencial analisar o currículo e a formação docente como algo em constante construção.

Palavras-chave: Currículo. Educação. Estudos de Gênero. Formação docente. Professores/as.

ABSTRACT: This article aims to problematize in the (initial and continued) teacher training the importance of working and discussing gender relations in the school space. For this, we start from a bibliographical research. This research is in the field of Gender Studies, curriculum and teacher training. We consider the need to work with this theme in the school trying to get teachers to problematize and reflect their pedagogical practices. It is interesting to reflect on the disciplines, methodologies and contents from the perspective of gender studies. Thus, it is essential to analyze curriculum and teacher education as something in constant construction.

Keywords: Curriculum. Education. Gender Studies. Teacher training. Teachers.

\section{INTRODUÇÃO}

Na rotina escolar é comum professores/as focarem nos conteúdos ditos científicos e, na maioria das vezes, cumprir o papel de reprodutor de conteúdos. Em geral, o ambiente escolar molda os espaços e comportamentos para meninos e meninas com as características de gênero esperadas pela sociedade, muitas vezes, sem uma reflexão prévia.

O presente artigo problematiza a formação docente situada nos estudos de gênero, bem como, em seus currículos. Essa investigação pretende colaborar para que gênero seja

Educação, Psicologia e Interfaces, Volume 2, Número 3, p. 38 - 46, Setembro/Dezembro, 2018. 
um tema refletido na formação docente. A formação de professores/as é um tema importante a ser abordado e refletido, pois o cotidiano docente é bastante amplo e complexo. Desta forma, é necessário que haja uma reflexão plural e multifacetada, possibilitando abranger todos/as.

Bezerra e Mendes (2016, p.01) apontam que a escola caracteriza "uma das maiores fontes de formação ideológica, política e de cidadania, assim, há a necessidade de construirmos uma cultura de paz, tolerância e respeito, de forma participativa e democrática". Pretendo, neste texto, dialogar com artigos, livros e dissertações que abordem da formação docente, currículo e estudos de gênero.

Discutir e indagar a importância dos estudos de gênero serem inseridos e propostos nos currículos e na formação docente significa por em xeque as relações de poder estabelecidas social e culturalmente. O currículo precisa ser compreendido como um campo do conhecimento, e como tal, é importante que seja flexível quanto a diversidade dos sujeitos e seus conhecimentos. É interessante refletir sobre a construção dos currículos nos espaços escolares e percebê-los como artefato de cultura. Braga (2014, p.48) ressalta que o currículo "é uma produção cultural que constrói, materializa, normaliza e ensina subjetividades para além da experiência na escola”.

Para a investigação, nos pautaremos numa pesquisa qualitativa do tipo bibliográfica nos/as principais autores/as pós-críticos que abordem Currículo e Gênero e Formação docente. Silva (2010); Macedo (2010); Paraíso (2010); Louro (2005); Arroyo (2011) e Braga (2014) são autores/as primordiais que abordam reflexões sobre os temas citados.

Torna-se essencial analisar o currículo e a formação docente como algo em constante construção, bem como, refletir sobre as disciplinas, metodologias e conteúdos sob a perspectiva dos estudos de gênero. Nessa direção, a abordagem das questões de gênero no espaço escolar é primordial para promover a cultura e respeito às diferenças, corroborando na construção de uma sociedade para todos/as.

\section{MATERIAL E MÉTODO}

Educação, Psicologia e Interfaces, Volume 2, Número 3, p. 38-46, Setembro/Dezembro, 2018.

ISSN: 2594-5343. DOI: https://doi.org/10.37444/issn-2594-5343.v2i3.85 
A metodologia adotada nesse artigo foi a bibliográfica que de acordo com Cervo e Bervian (1996) é caracterizada pelo estudo de materiais já existentes. Nessa direção Gil (2002, p.45) indica que a pesquisa bibliográfica é desenvolvida:

Com base em material já elaborado, constituído principalmente de livros e artigos científicos. Embora em quase todos os estudos seja exigido algum tipo de trabalho dessa natureza, há pesquisas desenvolvidas exclusivamente a partir de fontes bibliográficas.

Quanto à natureza, o estudo se caracteriza como qualitativo, pois busca aprofundar a discussão sobre a temática de gênero, currículo e formação docente. E também esse estudo pode ser considerado exploratório, que segundo Gil (2002) tem o objetivo de aprimorar ideias. Dessa maneira, a presente pesquisa se caracteriza como qualitativa, exploratória e bibliográfica, pois busca refletir sobre o tema problematizado a partir de autores/as clássicos e contemporâneos.

\section{RESULTADOS E DISCUSSÃO}

A caracterização de Lauretis (1994, p.212) sobre gênero considerou uma "construção cultural do sexo em gênero e a assimetria que caracteriza todos os sistemas de gênero através das diferentes culturas [...]". As construções de homem e mulher são um produto social e cultural e dialogando com esta afirmação, Carvalho (2003, p. 59), indica que "feminilidade e masculinidade têm significados instáveis e plurais, ao mesmo tempo em que integram uma estrutura de dominação".

Desta maneira, na formação docente é importante discutir a questão das relações de gênero, isto é, conversar com os/as educadores/as em formação, sobre como as práticas pedagógicas estão diretamente ligadas à construção do indivíduo, e sobre seu significado social enquanto homem e mulher.

Esta discussão necessita ser organizada em torno de possibilidades estratégicas de transformar o espaço educacional. É necessário que os/as educadores/as se conscientizem que a educação é um processo constante, flexível, fluído e cambiante.

Arroyo (2011, p.26) sinaliza que "a própria mística da docência como ideal profissional entra em crise quando nosso foco na sala de aula está entre o passar a matéria ou a educação". É notório que muitos/as professores/as sentem-se sobrecarregados/as nas diversas atividades a serem propostas e praticadas em sala de aula, porém é necessário que haja essa reflexão quanto às práticas na formação docente. 
Segundo Costa (2001) o currículo como um texto que traz muitas histórias, sobre "indivíduos, grupos sociedades, culturas e tradições", demonstrando o modelo "correto" das coisas. No âmbito da teoria curricular, constatamos que nas últimas décadas houve certa evidência na formação docente. Moreira (1999, p.88), destaca que "parece consensual o ponto de vista de que é necessário lidar com os preconceitos e os estereótipos dos futuros professores". Complementando este pensamento, Meyer e Soares (2004, p.11), abordam que, na realidade, os/as professores/as "tendem a se apoiar em abordagens normativas" e na prática em sala de aula, em suas ações acabam por "classificar e diferenciar [...] o que é normal e o que é desviante".

Para Moreira e Silva (1994, p.27) "a cultura é o terreno em que se enfrentam diferentes e conflitantes concepções de vida social, é aquilo pelo qual se luta não aquilo que recebemos”. Na sicussão acerca do currículo Paraíso (2010, p. 3) afirma que

[...] além de ensinar muito sobre gênero, também operam, nos mais diferentes ensinamentos, com pensamentos e raciocínios generificados que atribuem capacidades distintas a meninos e meninas, a homens e mulheres, cobram "condutas adequadas" a seu sexo e "confinam" certos/as estudantes a uma compreensão de si mesmo como faltosos, problemáticos e fora da regra.

Nesta perspectiva, é necessário trabalhar alguns aspectos: refletir sobre a atual situação da formação docente e do currículo e criar estratégias que melhorem as lacunas percebidas na prática. A educação planejada com os estudos de gênero surge como um movimento de luta, que visa romper as barreiras criadas e materializadas em comportamentos femininos e masculinos. Sobre currículo, Costa (2001, p. 51) aponta:

É um lugar de circulação de narrativas, mas, sobretudo, é um lugar privilegiado dos processos de subjetivação, da socialização dirigida, controlada. É em grande parte à escola que tem sido atribuída a competência para concretizar um projeto de indivíduo para um projeto da sociedade. Mesmo as narrativas que se intitulam 'emancipatórias' anunciam a centralidade da escola na tarefa de produzir subjetividades adequadas ao que tais projetos consideram desejável, o que evidencia uma forma muito peculiar de emancipação. Seria mais ou menos o mesmo que falar em 'emancipação dirigida'.

Torna-se, assim, fundamental conceber estratégias de gênero distintas para construir uma transformação nessas realidades. As escolas têm participação fundamental na construção da personalidade dos/as alunos/as. Assim, questionamos: qual o lugar do

Educação, Psicologia e Interfaces, Volume 2, Número 3, p. 38-46, Setembro/Dezembro, 2018. 
gênero na formação docente? Que indivíduo pretendemos formar? Quais alternativas que existem para o respeito às diferenças? Questionamentos como estes são primordiais para se inserirem numa formação docente, por exemplo. Quais conteúdos são importantes para formação de docentes?

Para refletir sobre as fronteiras da abordagem das questões de gênero nos currículos da formação docente, faz-se necessário organizar algumas maneiras de desenvolver a compreensão de gênero no espaço escolar. Uma delas é dialogando diretamente sobre as relações de poder que estão essencialmente ligadas às questões de gênero. Outra maneira é dar prioridade e oportunidades de serem inseridas nos currículos para possibilitar a reflexão de como são construídas as identidades masculinas e femininas. Sobre a possibilidade de ampliar os significados das experiências dos/as educadores/as de classe, etnia, raça, gênero campo ou periferia se incorporem como algo a ser estudado, Arroyo (2011, p.125) indica:

Tentativas tensas, uma vez que os currículos e o material didático carregam um déficit de experiência e têm dificuldade de reconhecer ainda as experiências sociais nem sequer dos educandos e dos educadores como conhecimento devido, sistematizado.

Bourdieu (1999) indica que a escola reproduz e transforma de maneira simultânea as diferenças de gênero "devido às contradições que nela ocorrem e às que ela própria introduz" (p.105). Ao observarmos o espaço de formação docente, na atualidade, constatamos a amplitude dos modos como é construída tal formação, além da formação há uma legislação, documentação a ser seguida e que regulamentam os processos educativos. Giroux (1995, p.86) aponta que:

Como instituições ativamente envolvidas em formas de regulação moral e social, as escolas pressupõem noções fixas de identidade cultural e nacional e os/as educadores/as, ao agirem como agentes na produção, circulação e uso de formas particulares de capital cultural e simbólico, ocupam um inevitável papel político.

Dessa forma, a escola enquanto espaço formador de personalidade proporciona um ambiente favorável para alguns e produz /limita a desigualdade e submissão de outros. É importante olhar para dentro das escolas e dos currículos no intuito de perceber quais as histórias vem sendo produzidas e reproduzidas e como gênero atravessa esse percurso. 
A frase famosa de Beauvoir, "ninguém nasce mulher, torna-se mulher" é comprovada quando refletimos que o espaço escolar, por exemplo, limita e molda comportamentos ditos femininos e masculinos. Situações onde professores e professoras recriminam e impõem situações por conta do gênero. "Sente-se como uma mocinha; Menino não chora”. São frases que certamente todos/as ouvimos enquanto crianças e até reproduzimos enquanto adultos. Portanto é fundamental que haja uma reflexão acerca dos comportamentos e espaços pré-determinados por seu gênero.

Braga (2014) indica que "as experiências na escola tradicional e conhecimento escolar não podem ser considerados apenas como um processo neutro de reprodução (p.48)”. Complementando a ideia, Louro (2001, p. 88) nos traz sua reflexão:

O currículo "fala" de alguns sujeitos e ignora outros; conta histórias e saberes que, embora parciais, se pretendem universais; as ciências, as artes e as teorias trazem a voz daqueles que se auto atribuíram a capacidade de eleger as perguntasse construir as respostas que, supostamente, são de interesse de toda a sociedade.

Como pudemos observar, as escolas e os currículos estão longe de serem espaços igualitários e neutros. Félix (2015, p. 226) diz que "o currículo nunca é neutro: desde a seleção dos conteúdos, autores/as, materiais didáticos [...]”. Junto a sua construção, eles vêm carregados de práticas e atividades tidas como "naturais" onde na verdade são carregados de sexismo e patriarcado.

Ao refletir sobre os desafios de tratar de gênero nos currículos e nas práticas pedagógicas, Félix (2012, p.225), expõe que “estes temas vêm sendo considerados 'polêmicos', secundários, desnecessários, por docentes e outros/as trabalhadores/as das escolas, mas também por gestores/as públicos e por uma parcela importante e significativa da sociedade".

É fundamental um trabalho de formação e reflexão sobre as questões das relações de gênero, do machismo e da homofobia. Torna-se primordial criar uma pedagogia compromissada com a transformação das situações citadas, que ainda são tão corriqueiras na atualidade. Contribuindo com este pensamento, Maria Cláudia Dal'Igna (2011, p.49) explicita que:

Tomar o conceito de gênero como um elemento organizador da cultura possibilita examinar os diferentes modos pelos quais gênero opera estruturando o próprio social. Sob essa perspectiva, abandona-se o

Educação, Psicologia e Interfaces, Volume 2, Número 3, p. 38-46, Setembro/Dezembro, 2018. 
entendimento de que gênero se refere apenas à construção social de papeis em funções masculinos e femininos. Tal abordagem remeteria a uma individualização dos processos de produção de diferenças e desigualdades de gênero e deixaria de problematizar como tais diferenças e desigualdades são produzidas no interior das instituições e práticas sociais, as quais são constituídas pelos - e constituintes dos gêneros.

Supõe-se que a escola e a universidade acatam a participação de seus discentes em formação para a docência, possibilitando elaborar estratégias que supram as necessidades identificadas por seus estudantes. Na maioria das vezes, a estrutura da formação de professores/as resume-se em aprender modelos pré-estabelecidos no intuito de serem reproduzidos na prática docente.

É importante que os estudos das relações de gênero estejam inseridos nos diálogos dos/as docentes em suas formações. Parto do pressuposto que não haja uma formação no sentido de conclusão, mas sim algo em constante (re)construção e (re)flexão. "Dessa forma, o investimento na formação docente é imprescindível, mas não é qualquer formação; tem que ser uma formação pautada em uma concepção de superação à lógica racionalidade técnica, ou seja, um pensamento e proposta de formação para que os professores possam refletir e agir sobre sua organização do trabalho pedagógico".

\section{CONSIDERAÇÕES FINAIS}

Definidos como polos excludentes, os gêneros compõem uma relação de poder, construindo representações sociais e atribuindo significados. O conceito de gênero se baseia num constructo social, histórico e cultural. A feminilidade e a masculinidade têm valores que variam de acordo com a localidade, tornando-se fluídas e plurais.

É interessante refletir sobre as disciplinas, metodologias e conteúdos sob a perspectiva dos estudos de gênero. Assim, torna-se essencial analisar o currículo e a formação docente como algo em constante construção.

Portanto, é importante problematizar com os/as professores/as sobre a relação entre seus valores e práticas em sala de aula. Isto é, estimular romper a crença de neutralidade nas práticas pedagógicas. Auxiliando no desenvolvimento de um senso crítico acerca dos valores que são construídos e reproduzidos socialmente, naturalizandose sem, na maioria das vezes, uma reflexão prévia. Por exemplo, comportamentos masculinos e femininos. 


\section{REFERÊNCIAS BIBLIOGRÁFICAS}

ARROYO, M. G. Currículo, território em disputa. Petrópolis: Vozes, 2011.

BEZERRA, L. L. FÉLIX, J. Mulheres na Marinha Mercante: desafios e potencialidades de atuar num espaço masculino. ICONEPI- Congresso Nacional em Educação e Práticas Interdisciplinares. (Org.) Rosilene Félix Mamedes, Hermano Rodrigues de França. João Pessoa: Sal da Terra, 2017. p.457-465.

BOURDIEU, P. A dominação masculina. Rio de Janeiro: Bertrand Brasil, 1999.

BRAGA, D. Corpos estranhos se tornam matéria: identidades LGBT no currículo da escola. Curitiba: CRV, 2014.

CABRAL, F. MENDES. Reflexões sobre os Direitos Humanos no contexto da Educação Popular: introspecções e subjetividades à luz da educação emocional. IX Seminário Internacional de Direitos Humanos da UFPB. João Pessoa, 2016. Disponível em: $\quad$ www.ufpb.br/evento/lti/ocs/index.php/ixsidh/ixsidh/paper/download/4439/1688 Acesso em: 05/03/2018.

CERVO, A. BERVIAN, P. Metodologia científica. São Paulo: Makron Books, 1996.

FÉLIX. J. Gênero e Formação docente: reflexões de uma professora. Espaço do currículo, v.8, n.2, p.223-231, Maio a Agosto de 2015. Disponível em:

http://periodicos.ufpb.br/index.php/rec/article/viewFile/rec.2015.v8n2.223231/13923 Acesso em: 25/02/2018.

GIL, A. Como elaborar projetos de pesquisa. 4. ed. São Paulo: Atlas, 2002.

LAURETIS, T. A tecnologia do gênero. In: HOLLANDA, Heloisa Buarque de. Tendências e impasses: o feminismo como crítica da cultura. Rio de Janeiro:

Rocco, 1994. p. 212-217

LOURO, G. O currículo e as diferenças de gênero. COSTA, M.V.C. (org.) O currículo nos limiares do contemporâneo. Rio de Janeiro: DP\&A, 2001. (p.85-92)

GIROUX, H. Praticando estudos culturais nas faculdades de educação. In: SILVA, T. T. (org) Alienígenas na sala de aula. Petrópolis: Vozes, 1995.

MEYER, Dagmar Estermann; SOARES, Rosângela de Fátima R. Corpo, gênero e sexualidade nas práticas escolares: um início de reflexão. In: MEYER, Dagmar Estermann; SOARES, Rosângela de Fátima R. (orgs.). Corpo, gênero e sexualidade. Porto Alegre: Mediação, 2004

MOREIRA, A. F.; SILVA, T. T. (org.). Currículo, cultura e sociedade. São Paulo: Cortez, 1994. 
MOREIRA, A. F.. Multiculturalismo, currículo e formação de professores. In: MOREIRA, Antonio Flavio B. Currículo, políticas e práticas. Campinas: Papirus. 1999. p. 81-96.

PARAÍSO, M. A. Raciocínios generificados no currículo e possibilidades de aprender. In: Colóquio luso-brasileiro sobre questões curriculares. Colóquio sobre questões curriculares, Porto, 2010. Anais. Porto- Portugal, 2010.

\section{Credenciais da autora}

BEZERRA, Ludmila Lins. Mestra em Educação pela Universidade Federal Vales do Jequitinhonha e Mucuri - UFVJM. E-mail: ludlins_@ hotmail.com

Endereço para correspondência: Ludmila Lins Bezerra. E-mail:

ludlins_@hotmail.com

Como citar este artigo (Formato ABNT): BEZERRA, Ludmila Lins. Currículo, gênero e formação docentes. Educação, Psicologia e Interfaces, v.2, n.3, p. 38-46, 2018. DOI: https://doi.org/10.37444/issn-2594-5343.v2i3.85

Recebido: 04/02/2018.

Aceito: $26 / 05 / 2018$ 